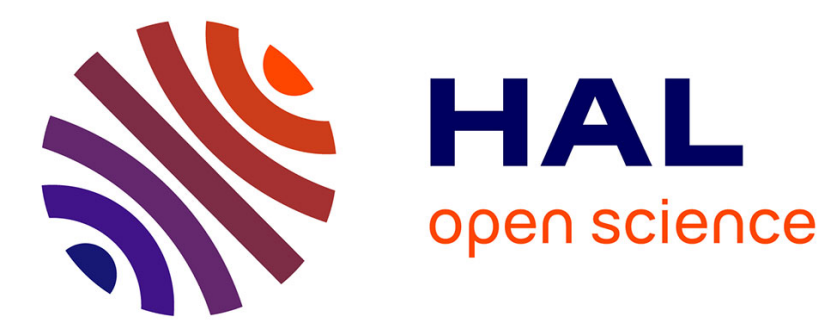

\title{
Isotropy of the Lamb-Mössbauer factor in ferrous fluosilicate single crystals (Debye model)
}

\author{
A. Cereze, M. Henry, F. Varret
}

\section{To cite this version:}

A. Cereze, M. Henry, F. Varret. Isotropy of the Lamb-Mössbauer factor in ferrous fluosilicate single crystals (Debye model). Journal de Physique Lettres, 1980, 41 (7), pp.157-159. 10.1051/jphyslet:01980004107015700 . jpa-00231748

\section{HAL Id: jpa-00231748 https://hal.science/jpa-00231748}

Submitted on 1 Jan 1980

HAL is a multi-disciplinary open access archive for the deposit and dissemination of scientific research documents, whether they are published or not. The documents may come from teaching and research institutions in France or abroad, or from public or private research centers.
L'archive ouverte pluridisciplinaire HAL, est destinée au dépôt et à la diffusion de documents scientifiques de niveau recherche, publiés ou non, émanant des établissements d'enseignement et de recherche français ou étrangers, des laboratoires publics ou privés. 


\title{
Isotropy of the Lamb-Mössbauer factor in ferrous fluosilicate single crystals (Debye model) (*)
}

\author{
A. Cereze, M. Henry and F. Varret \\ Laboratoire de Spectrométrie Mössbauer (**), Faculté des Sciences du Mans, F 72017 Le Mans Cedex, France
}

(Reçu le 20 juillet 1979, accepté le 18 février 1980)

Résumé. - Nous avons mesuré la variation thermique de la profondeur des raies Mössbauer de monocristaux de fluosilicate ferreux. Les résultats, corrigés des effets d'épaisseur effective, suivent correctement le modèle de Debye $\operatorname{avec} \theta_{\mathbf{D}}=180 \pm 13 \mathrm{~K}$; à la précision des mesures, le facteur Lamb-Mössbauer est isotrope $:\left|\left(f_{\|}-f_{\perp}\right) / f_{\|}\right|<8 \%$ à $30 \%$ selon la température.

\begin{abstract}
The Mössbauer line intensities of ferrous fluosilicate single crystals have been recorded as a function of temperature. The data, once corrected for thickness effects, follow the Debye model, with $\theta_{\mathrm{D}}=180 \pm 13 \mathrm{~K}$. The anisotropy of the Debye-Waller factor is smaller than the experimental accuracy : $\left|\left(f_{\|}-f_{\perp}\right) / f_{\|}\right|<8 \%$ to $30 \%$ according to the temperature.
\end{abstract}

1. Introduction. - Recently, the Goldanskii-Karyagin effect was proposed [1] as one of the phenomena associated with the asymmetrical shape of the quadrupolar spectra of ferrous fluosilicate powder samples [2].

In this paper, we report direct measurements, in single crystals, of the temperature dependence of the $\varepsilon$ parameter, where $\delta=\left(f_{\|}-f_{\perp}\right) / f_{\|}$characterizes the axial anisotropy of the Debye-Waller factor (this axial assumption will be discussed in section 4).

Detailed calculations of the Goldanskii-Karyagin effect are reported in [3] : $\varepsilon=k^{2}\left(\left\langle z^{2}\right\rangle-\left\langle x^{2}\right\rangle\right)$ is defined as a vibrational anisotropy parameter, and $f_{\perp} / f_{\|}=\exp \varepsilon$; the ratio $R$ of the quadrupolar lines intensities versus $\varepsilon$ is given. (Notice that $\varepsilon=-\varepsilon$ when both of these parameters are small.)

We use the expression of the effective thickness $T$, already defined in [4] :

$$
T=\operatorname{fan\sigma }_{0} t \frac{\Gamma_{0}}{\Gamma}
$$

where $f=$ Debye-Waller factor

$a n=$ number of ${ }^{57} \mathrm{Fe}$ atoms per $\mathrm{cm}^{3}$

$\sigma_{0}=$ effective cross section

$t=$ sample thickness in $\mathrm{cm}$

$\Gamma_{0}=$ natural width

$\Gamma=$ half height width of the absorber line.

(*) La version française de cet article a été acceptée aux Comptes Rendus de l'Académie des Sciences et est insérée dans le $\mathrm{n}^{\circ} \mathrm{du}$ 17 décembre 1979.

(**) ERA CNRS n" 682.
2. Measurements. - The direct measurement of $f$ by comparison with a black absorber implies a systematic error due to the different electronic absorptions in both types of absorbers.

The estimation of $f($ via $T)$ from measurements of the relative intensities of single crystal quadrupolar lines $[5 a]$ is disturbed when different broadenings occur on the quadrupolar components. (The use of such a method has already brought us to a patently under estimated $f$-value [6].)

Another method consists in considering the relative variation of the area of the Mössbauer lines during a set of experiments where temperature alone is changed.

In the limit of an infinitely thin absorber, the area of a given line, $\Gamma T$ is proportional to $f$.

$f$ is then assumed to follow the law calculated in the Debye model,

$$
\begin{aligned}
f_{\theta_{\mathbf{D}}}(\theta)=\exp \left\{-\frac{3 E_{\mathrm{R}}}{2 k \theta_{\mathrm{D}}}[\right. & 1+4\left(\frac{\theta}{\theta_{\mathrm{D}}}\right)^{2} \times \\
& \left.\left.\times \int_{0}^{\theta_{\mathbf{D} / \theta}} \frac{y \mathrm{~d} y}{\exp (y)-1}\right]\right\}
\end{aligned}
$$

where $\theta$ is the absorber temperature

$\theta_{\mathbf{D}}$ is the Debye temperature

$E_{\mathrm{R}}$ is the nuclear recoil energy $\left(E_{\mathrm{R} /} k=22.71 \mathrm{~K}\right.$ for ${ }^{57} \mathrm{Fe}$ ).

Therefore, on a logarithmic scale, the evaluation of $\theta_{\mathrm{D}}$ becomes theoretically possible, by comparison of 
the measured areas with the set of $f_{\theta_{\mathrm{D}}}(\theta)$ curves; then, the $f$-value is determined at any temperature.

Practically, effective thickness effects modify the line areas in the range of about $1 /\left(1+C_{i}^{\alpha} T / 4\right)[5,7]$ where $T$ is the so-called effective thickness and $C_{i}^{\alpha}$ a relative absorption probability of the $i$ th involved line.

These coefficients $C_{i}^{\alpha}$ (where $\alpha=\mathrm{I}, \mathrm{II}$ ) are the eigenvalues of the $\rho_{p q}^{i}$ tensor previously used by Housley et al. [7]; a general calculation for the $C_{i}^{\alpha}$ and their polarization $\alpha$ is given in [5].

Therefore, we must compare for each line the measured area with the following corrected expression :

$$
f_{\text {corr }(i)}(\theta)=\frac{f_{\theta_{\mathrm{D}}}(\theta)}{1+C_{i}^{\alpha} T / 4}=\frac{f_{\theta_{\mathrm{D}}}(\theta)}{1+f_{\theta_{\mathrm{D}}}(\theta) a n \sigma_{0} C_{i}^{\alpha} t / 4} .
$$

This formula involves a $5 \%$ error when $C_{i}^{\alpha} T=4.5$ (we consider this value as a reasonable limit). In addition, eq. (2) assumes that the width of the considered line is equal to that of the source : this assumption is based on the fact that both the line source and the considered line of the absorber are close to the natural width (experimental width of line 2, $\Gamma \sim 0.24 \mathrm{~mm} / \mathrm{s}$ for a thin absorber of fluosilicate powder at room temperature).

3. Results. - In order to determine $f_{\|}$and $f_{\perp}$ in ferrous fluosilicate, we have used :

- a platelet, cut perpendicularly to c-axis, $1.5 \mathrm{~mm} \pm 0.1 \mathrm{~mm}$ thick $\left(f_{\|}\right)$,

- a platelet, containing c-axis, $0.3 \mathrm{~mm} \pm 0.05 \mathrm{~mm}$ thick, obtained by cleaving, $\left(f_{\perp}\right)$.

Two spectra, showing the statistical qualities of the experiments are reproduced on figure 1 .

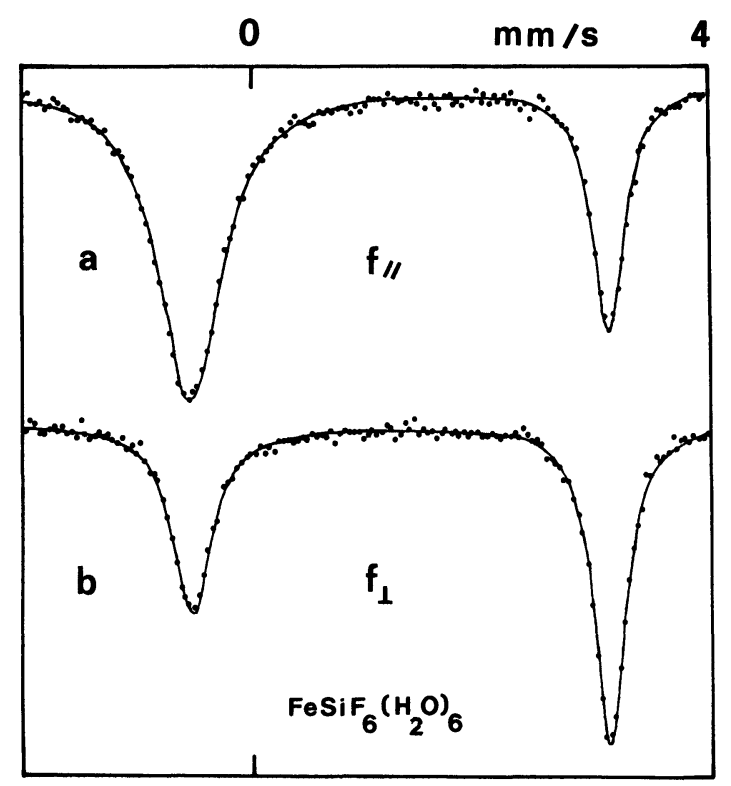

Fig. 1. - Room temperature spectra of lerrous fluoslicate : (a) c-axis perpendicular to the plate $\left(f_{\|}\right) ;(b)$ c-axis parallel to the plate $\left(f_{\perp}\right)$.
The most significant results deal with line 2 which remains narrow at any temperature, contrarily to line 1 [2].

The thickness correction has been applied with the following values (coefficients defined in [5]) :

$$
C_{2}^{\mathrm{I}}=C_{2}^{\mathrm{II}}=1 / 4
$$

(c-axis perpendicular to the platelet: I and II are circular polarizations).

$$
C_{2}^{\mathrm{I}}=1 / 4 ; C_{2}^{\mathrm{II}}=1
$$

(platelet containing c-axis: I and II are linear polarizations).

The correction implies two terms :

$f_{\text {corr (2) }}(\theta)=\frac{f_{\theta_{\mathrm{D}}}(\theta)}{C_{2}^{\mathrm{I}}+C_{2}^{\mathrm{II}}}\left[\frac{C_{2}^{\mathrm{I}}}{1+C_{2}^{\mathrm{I}} T / 4}+\frac{C_{2}^{\mathrm{II}}}{1+C_{2}^{\mathrm{II}} T / 4}\right]$

here, $a n \sigma_{0} t=31.7$ (c-axis perpendicular to the plate) $=6.3$ (c-axis parallel to the plate).

Figure $2 a$ shows the $f_{\text {corr }(2)}(\theta)$ curves; a logarithmic scale has been used so that the data, known to within an arbitrary scale factor, have been plotted on the graph safe for a vertical translation.

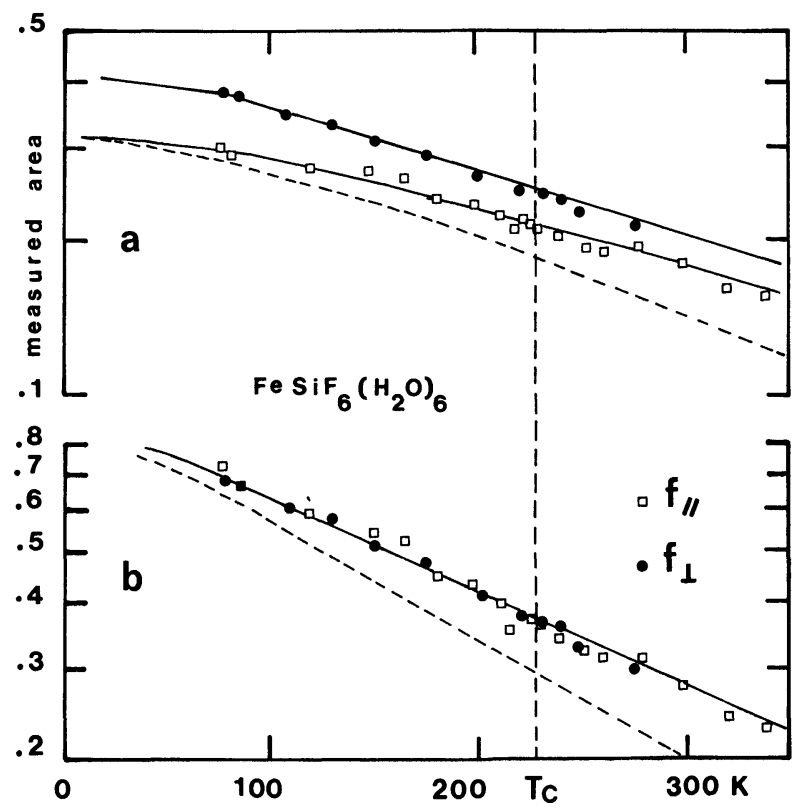

Fig. 2. $-(a) f_{\text {corr }}(\theta)$ calculated curves for $\theta_{\mathrm{D}}=180 \mathrm{~K}$ (full lines) and $\theta_{\mathbf{D}}=160 \mathrm{~K}$ (dashed lines). Experimental results : ( $\left.\square\right) \mathbf{c} \perp$ to the plate; $(\bullet) \mathbf{c} / /$ to the plate. (b) Experimental results : thermal variation of $f_{\|}$and $f_{\perp}$ and comparison with $f_{\theta_{\mathbf{D}}}(\theta)$ curves $: \theta_{\mathbf{D}}=180 \mathrm{~K}$ (full lines), $160 \mathrm{~K}$ (dashed lines).

Calculated curves match the experimental data when $\theta_{\mathrm{D}}$ is approximatively $180 \mathrm{~K}$ for both absorbers. Without thickness corrections, $\theta_{\mathrm{D}}$ values would be about $230 \mathrm{~K}$ (c-axis $\perp$ to the plate) and $200 \mathrm{~K}$ (caxis $/ /$ to the plate). 
The uncertainties on $\theta_{\mathrm{D}}$ can be evaluated as follows :

(i) The graphical uncertainty should not exceed $5 \mathrm{~K}$.

(ii) The relative uncertainty on platelet thickness (respectively $1 / 15$ and $1 / 6$ ) contributes about $3 \mathrm{~K}$ in both cases. Thus, we can admit, at this step,

$$
\theta_{\mathrm{D}}=180 \pm 8 \mathrm{~K} \text {, }
$$

and consequently,

$$
\left|\theta_{\mathrm{D}}\left(f_{\|}\right)-\theta_{\mathrm{D}}\left(f_{\perp}\right)\right| \leqslant 16 \mathrm{~K}
$$

(iii) The error due to the assumption that the source and absorber (line 2) have equal line widths is not easy to estimate accurately. There is no simple expression for the line area when the source and absorber line widths are different. Tentatively, one might assume a difference less than $0.01 \mathrm{~mm} / \mathrm{s}$ between these two widths. Then, the error on effective thickness is smaller than $10 \%$. That yields a $\theta_{\mathrm{D}}$ deviation occurring with the same sign in both experiments, smaller than $5 \mathrm{~K}$ for $f_{\|}$and $2 \mathrm{~K}$ for $f_{\perp}$, and leads to an additional error of less than $3 \mathrm{~K}$ for the difference

$$
\left|\theta_{\mathrm{D}}\left(f_{\|}\right)-\theta_{\mathrm{D}}\left(f_{\perp}\right)\right|
$$

(iv) At last, the error introduced by using the approached formula (eq. (2)) can be neglected (it will be shown in next section that the condition of validity of eq. (2) is fulfilled).

Thus we finally give :

$$
\begin{array}{ll}
\theta_{\mathrm{D}}=180 \pm 13 \mathrm{~K} & \left(f_{\|}\right) \\
\theta_{\mathrm{D}}=180 \pm 10 \mathrm{~K} & \left(f_{\perp}\right)
\end{array}
$$

and

$$
\left|\theta_{\mathrm{D}}\left(f_{\|}\right)-\theta_{\mathrm{D}}\left(f_{\perp}\right)\right| \leqslant 19 \mathrm{~K}
$$

4. Discussion. - To the maximum difference $\left|\theta_{\mathrm{D}}\left(f_{\|}\right)-\theta_{\mathrm{D}}\left(f_{\perp}\right)\right| \sim 20 \mathrm{~K}$, estimated above, corresponds an upper limit of the anisotropy of $f$, which is temperature dependent :

$$
\begin{aligned}
& |\&|<0.08(77 \mathrm{~K}) \\
& |\S|<0.30(300 \mathrm{~K}) .
\end{aligned}
$$

It is worth comparing these results with those of previous experiments on powders. According to [3], when $\delta$ is small, the relation

$$
|\varepsilon| \sim|\varepsilon| \sim 5 \times|1-R|
$$

is approximately obeyed ( $R$ is the ratio of the quadrupolar lines intensities involved in the GoldanskiiKaryagin effect).

From powder results reported in [2], we can assert that $|1-R|<0.08$ in the whole range of temperature. Consequently the resulting limitation for $|\varepsilon|$ of 0.4 does not disagree with the present results, but indicates that the present measurements on single crystals give more accurate informations than the previous experiments on powder samples.

$f$ values deduced from the present study are shown in figure $2 b: f(300 \mathrm{~K}) \sim 0.28$ is in good agreement with a previous determination $(f \sim 0.30)$ based upon birefringence experiments [8].

Once $f$ has been determined, it is possible to check that the condition of validity of eq. (2) is fulfilled : In the involved range of temperature, the $C_{i}^{\alpha} T$ factors amounts to 5.5 (c-axis $\perp$ to the plate) and 4.4 (c-axis $/ /$ to the plate) as a maximum; these values do not exceed too much the maximum allowed value.

Let us now consider the results near the $\mathrm{P} \overline{3} \mathrm{ml} \leftrightarrow \mathrm{P} 22_{1} / \mathrm{c}$ transition temperature, i.e. $T_{\mathrm{c}}=225 \mathrm{~K}$; both platelets lead to smooth data, excluding any sharp change in $f_{\|}$and $f_{\perp}$.

Any possible change at $T_{\mathrm{c}}$ in the $f$-anisotropy parameter, $\varepsilon=\left(f_{\|}-f_{\perp}\right) / f_{\|}$, is smaller than 0.05 . This result confirms previous powder measurements [2] which showed that the $R$ ratio did not sizeably change near $T_{\mathrm{c}}$ (according to [3], $\Delta \varepsilon \leqslant 0.05$ corresponds to $\Delta R \leqslant 10^{-2}$ ). The lack of any anomaly in the thermal evolution of $f$ at $T_{\mathrm{c}}$ makes unnecessary the introduction of a non axial anisotropy of $f$ below $T_{\mathrm{c}}$.

5. Conclusion. - The Debye-Waller factor does not show any sizeable anomaly when passing through the $\mathrm{P} \overline{3} \mathrm{ml} \leftrightarrow \mathrm{P} 2_{1} / \mathrm{c}$ transition : neither in the average value nor in the axial anisotropy of $f$, in conflict with the conclusions of [1]. Therefore a $f$-anisotropy cannot be associated with the sharp change in the quadrupolar spectrum asymmetry at $T_{\mathrm{c}}$.

In the whole studied temperature range $f_{\|}$and $f_{\perp}$ correspond to a $180 \pm 13 \mathrm{~K}$ Debye-temperature ; $f$ is isotropic within the experimental accuracy. By no means can an anisotropy of $f$ be responsible for the asymmetry of the powder spectra of ferrous fluosilicate.

\section{References}

[1] Spiering, H., Vogel, H., Irler, W., Phys. Status Solidi (b) 82 (1977) 243

[2] Chappert, J., Jehanno, G., Varret, F., J. Physique 38 (1977) 411.

[3] Shenoy, G. K., Friedt, J. M., Nucl. Instrum. Methods 136 (1976) 569.

[4] Margulies, S., Ehrman, J. R., Nucl. Instrum. Methods 12 (1961) 131. [5a] Henry, M., Thèse 3e cycle, Le Mans (1979).

[5b] Henry, M., Teillet, J., Varret, F., Revue Phys. Appl. (to be published).

[5c] Henry, M., Varret, F., Revue Phys. Appl. 14 (1979) 289.

[6] Henry, M., Varret, F., Phys. Status Solidi (a) 44 (1977) 601.

[7] Housley, R. M., Grant, R. W., Gonser, U., Phys. Rev. 178 (1969) 514.

[8] Imbert, P., Thèse (1965), Orsay et $J$. Physique 27 (1966) 429. 